\title{
Coinfecção por Anaplasma platys e Ehrlichia canis em cães diagnosticada pela PCR
}

\author{
Co-infection by Anaplasma platys and Ehrlichia canis in dogs diagnosed by PCR \\ Valéria Régia Franco Sousa ${ }^{1}$, Teresa Cristina Bergamo do Bomfim², \\ Arleana do Bom Parto Ferreira de Almeida', Luciano Antunes Barros', \\ Kátia Gouveia Sales ${ }^{3}$, Christiano Henrique da Silva Justino ${ }^{3}$ \& Luciana Dalcin ${ }^{4}$
}

\begin{abstract}
RESUMO
O Anaplasma platys é o agente de uma doença branda conhecida como trombocitopenia cíclica canina, que cursa frequentemente com trombocitopenia e parasitemia das plaquetas, a cada quatorze dias. Alguns recentes relatos têm descrito uma doença severa principalmente associada à infecção por Ehrlichia canis. Este relato descreve os principais achados clínicos, hematológicos e bioquímicos da coinfecção por A. platys e E. canis diagnosticada através da PCR e nested PCR, usando oligonucleotídeos específicos. Os cães apresentavam sinais inespecíficos, sem distúrbios hemostáticos como trombocitopenia, considerado principal achado da infecção por A. platys e comum na E. canis. Anemia foi observada nos dois casos, e em nenhum houve alteração nos níveis séricos de ureia, creatinina, alanino aminotransferase e fosfatase alcalina. Em um cão, observou-se hiperglobulinemia, decorrente da resposta imune, concordando com a literatura que cita exacerbação clínica associada a este tipo de coinfecção.
\end{abstract}

Descritores: cães, Anaplasma platys, Ehrlichia canis, PCR.

\begin{abstract}
The Anaplasma platys is an agent of a mild canine thrombocytopenia cyclical disease, which often develops with thrombocytopenia and parasitemia of platelets, every fourteen days. Some recent reports have described a severe disease mainly associated with Ehrlichia canis infection. This report describes the main clinical, biochemical and hematological of co-infection with A. platys and E. canis diagnosed by PCR and nested PCR, using specific primers. The dogs had non-specific signs, haemostatics without disruption as thrombocytopenia considered main finding of infection by A. platys and common in E. canis. Anemia was observed in both cases, and there was no change in serum levels of urea, creatinine, alanine aminotransferase, and alkaline phosphatase. In a dog was observed hyperglobulinemia, resulting from the immune response, agreeing with the literature that reports clinical exacerbation in this type of co-infection.
\end{abstract}

Keywords: dogs, Anaplasma platys, Ehrlichia canis, PCR.

${ }^{1}$ Departamento de Clínica Médica Veterinária, Faculdade de Medicina Veterinária (FAMEV), Universidade Federal do Mato Grosso (UFMT), Av. Fernando Correa da Costa s/n., Coxipó, CEP 78060-900 Cuiabá, Mato Grosso, MT, Brasil. ${ }^{2}$ Departamento de Parasitologia Veterinária, Universidade Federal Rural do Rio de Janeiro (UFRRJ), Seropédica, RJ. ${ }^{3}$ Médico Veterinário autônomo. ${ }^{4}$ Curso de Pós-graduação em Ciência Animal, Universidade de Brasília (UnB), DF. Correspondência: V.R.F Sousa [regia@ufmt.br ; Fax 55 + (65) 3615 8664]. 


\section{INTRODUÇÃO}

Anaplasma platys, anteriormente Ehrlichia platys, é uma bactéria que infecta apenas plaqueta de cães induzindo a trombocitopenia cíclica, possuindo como provável vetor o carrapato Rhipicephalus sanguineus $[8,11]$. A trombocitopenia cíclica canina é considerada uma doença benigna, apresentando como sinais clínicos febre, depressão e anorexia, além de trombocitopenia cíclica, discreta anemia normocítica normocrômica arregenerativa, leucopenia, hipoalbuminemia e hiperglobulinemia $[2,10]$.

Como os sinais associados com a trombocitopenia cíclica canina não são específicos, o diagnóstico necessita de exames complementares. A parasitemia cíclica do agente torna a observação de mórulas difícil levando a resultados falso negativos. A reação em cadeia de polimerase é útil na detecção de $A$. platys no estágio inicial da infecção assim como na fase crônica da doença [2].

O propósito deste relato é descrever dois casos de coinfecção por Anaplasma platys e Ehrlichia canis em cães através da observação de mórulas no esfregaço sanguíneo e amplificação do DNA pela PCR, destacando os principais achados clínicos, hematológicos e bioquímicos.

\section{RELATO DE CASO}

No Setor de Clínica Médica do HOVET da UFMT, foram atendidos dois cães, residentes na área urbana de Cuiabá, adultos, sendo uma fêmea e um macho. $\mathrm{O}$ primeiro cão foi atendido apresentando febre, esplenomegalia e osteomielite secundária a fratura exposta da tíbia e fíbula esquerda, e o segundo com queixa de vômito, perda de peso e com tumor venéreo transmissível canino. Após o exame clínico, foram obtidas amostras sanguíneas para avaliação hematológica, bioquímica sérica visando à avaliação hepática, renal, bem como mensuração das proteínas plasmáticas [7], e para amplificação de DNA pela PCR, assim como foram confeccionados esfregaços sanguíneos para a pesquisa de formas evolutivas de A. platys e Ehrlichia canis.

A extração de DNA foi realizada com o Mini Kit QIAmp DNA Blood (Qiagen $\left.{ }^{\circledR}\right)$, conforme instruções do fabricante, enquanto na PCR utilizou-se primers PLATYS -F (5'- aag tcg aac gga ttt ttg tc - 3') e PLATYS -R" (5'- ctt taa ctt acc gaa cc - 3'), para A. platys [4] e ECC (5'- aga acg aac gct ggc ggc aag cc - 3') e ECB
(5'- cgt att acc gcg gct gct ggc - $\left.3^{\prime}\right)$, para E. canis [9]. Uma segunda etapa de amplificação (nested $\mathrm{PCR}$ ) para o A. platys, foi realizada com as mesmas condições da reação de PCR. Os produtos amplificados foram submetidos à eletroforese em Gel de Agarose e visualizados em transluminador.

\section{DISCUSSÃO}

Os cães com infecção por Anaplasma platys eram adultos, um de raça pura, macho e outro mestiço, fêmea, sendo que apenas o primeiro apresentava infestação por carrapatos, Rhipicephalus sanguineus. Apesar de não comprovado cientificamente, tal fato sugere esta via de transmissão, para um dos cães, todavia novos estudos devem ser delineados para se analisar a cadeia de transmissão assim como os fatores de risco, já que relatos sugerem maior incidência em cães jovens e de raça pura $[3,5]$.

Nos dois casos, foram identificados sinais clínicos inespecíficos como apatia, febre, linfoadenopatia e perda de peso. Relatos descrevem os referidos sinais como os principais, além de palidez de membranas mucosas e secreção nasal mucopurulenta. Nenhum distúrbio de hemostasia primária foi observado, da mesma forma que não se observou redução na contagem plaquetária, como é descrito na infecção aguda por tal agente [3].

Os cães exibiram anemia normocítica hipocrômica, sugerindo infecção crônica. Em um dos cães com infecção por $A$. platys, foi visualizado macroplaquetas, condizente com outros estudos [1,3]. No entanto, a preponderância de plaquetas grandes com granulações esparsas sugere aumento da produção e liberação de plaquetas na circulação, sendo achadas ocasionalmente em animais normais [6]. A contagem global de leucócitos encontrava-se diminuída, bem como as proteínas séricas totais, tanto albumina como globulina em um dos cães com infecção associada a $A$. platys, enquanto, no outro, verificou-se hiperglobulinemia, hipoalbuminemia, resultados estes que corroboram com a literatura [1]. Nenhum dos cães apresentou alteração nos níveis séricos de ureia, creatinina, alanino aminotransferase e fosfatase alcalina.

O diagnóstico inicial de trombocitopenia cíclica canina foi através da observação de mórulas em plaquetas no esfregaço sanguíneo, técnica rápida e de baixo custo, no entanto pouco sensível. Após a nested PCR, além de confirmar a presença de A. platys (Figura 1) em cães da região de Cuiabá, Mato Grosso, demonstrou-se coinfecção 
com Ehrlichia canis, um achado descrito em áreas endêmicas para ehrlichiose, com gravidade clínica mais severa, podendo ter influenciado tanto os achados clínicos como hematológicos e bioquímicos [2,3].

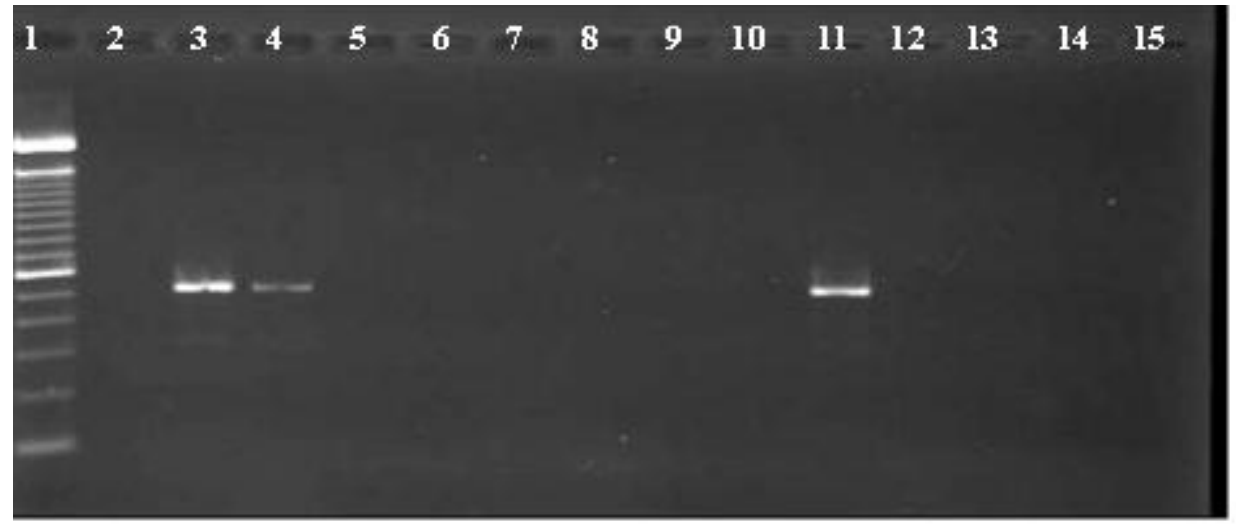

Figura 1. Nested PCR de Anaplasma platys com primers Platys-F/Platys-R (produto $504 \mathrm{pb}$ ) de cães atendidos no HOVET UFMT. Linha 1 - marcador de tamanho molecular (100 pb); linha 3 - controle positivo; linhas 4 a 15 - amostras testadas e linha 2 - controle negativo.

\section{REFERÊNCIAS}

1 Baker D.C., Gaunt S.D. \& Babin S.S. 1988. Anemia of inflammation in dogs infected with Ehrlichia platys. American Journal of Veterinary Research. 49: 1014-1016.

2 Chang W.L. \& Pan M.J. 1996. Specific amplification of Ehrlichia platys DNA from blood specimen by two-step PCR. Journal of Clinical Microbiology. 34: 3142-3146.

3 Harrus S., Aroch I., Lavy E. \& Bark H. 1997. Clinical manifestations of infectious canine cyclic thrombocytopenia. Veterinary Record. 141: 247-250.

4 Inokuma H.D., Ohno K., Onishi T, Raoult D. \& Brouqui P. 2001. Detection of ehrlichial infection by PCR in dogs from Yamaguchi and Okinawa Prefectures, Japan. Journal of Veterinary Medicine Science. 63: 815-817.

5 Inokuma H.D., Raoult D. \& Brouqui P. 2000. Detection of Ehrlichia platys DNA in brown dog ticks (Rhipicephalus sanguineus) in Okinawa Island, Japan. Journal of Clinical Microbiology. 38: 4219-4221.

6 Jain N.C. 1993. Essentials of Veterinary Hematology. Philadelphia: Lea \& Febiger, 417p.

7 Kaneko J.J., Harvey J.W. \& Bruss M.L. 1997. Clinical biochemistry of domestic animals. 5th edn. San Diego: Academic Press, 932p.

8 Mcdade J.E. 1990. Ehrlichiosis - a disease of animals and humans. The Journal of Infectious Disease. 161: 609-617.

9 Murphy G.L., Ewing S.A., Whitworth L.C., Fox J.C. \& Kocan A.A. 1998. Molecular and serologic survey of Ehrlichia canis, Ehrlichia chaffeensis, and E. ewingii in dogs and ticks from Oklahoma. Veterinary Parasitology. 79: 325-339.

10 Rikihisa Y. 1991. The tribe Ehrlichiae and ehrlichial diseases. Clinical Microbiology Review. 4: 286-308.

11 Simpson R.M., Gaunt S.D., Hair J.A., Kocan K.M., Henk W.G. \& Casey H.W. 1991. Evaluation of Rhipicephalus sanguineus as a potential biologic vector of Ehrlichia platys. American Journal of Veterinary Research. 52: 1537-1541. 